\title{
El giro neutralista del Partido Comunista argentino y los efectos sobre su alianza con el Partido Socialista (1939-1941)
}

\author{
Gabriel Piro Mittelman
}

UBA

gabrielpiro90@gmail.com

Title: The neutralist turn of the Argentine Communist Party and the effects on its alliance with the Socialist Party (1939-1941)

Resumen: Entre agosto de 1939 y junio de 1941, el Partido Comunista Argentino (PC), en sintonía con la Internacional Comunista, adoptó una posición neutralista frente a la Segunda Guerra mundial, tras la firma del tratado Molotov-Ribbentrop. En este artículo analizaremos el impacto que tuvo este cambio de estrategia respecto del período de "Frente Popular", en el desarrollo político de esta corriente durante dicho lapso. En particular observaremos el efecto de este viraje en su relación con el Partido Socialista (PS), a partir de los cambios efectuados en sus principales definiciones politicas.

Palabras clave: Partido Comunista Argentino - Segunda Guerra Mundial - neutralismo - Partido Socialista.

\begin{abstract}
Abstact: Between August of 1939 and June of 1941, the Argentine Communist Party (ACP), in the line of the Communist International, adopted a neutral position regarding WWII, after the signing of the Molotov-Ribbentrop treatment. In this article, we will try to analyze the impact this change of strategy elicited on the political development of the ACP during those years. In particular, we will discuss the effect of this shift in its previous system of alliances, especially with the Socialist Party, based on the changes made in its main political definitions. Key words: Argentine Communist Party - World War II - neutralism - Socialist Party
\end{abstract}

Recepción: 14 de noviembre de 2018. Aceptación: 8 de febrero de 2019 . 


\section{Introducción}

La toma de decisiones en el régimen soviético, concentrada a partir del ascenso de Stalin al liderazgo del buró político del Partido Comunista de la Unión Soviética, tras la muerte de Lenin en 1924, tuvo impacto no sólo en la politica rusa, sino en el conjunto de las organizaciones pertenecientes a la Internacional Comunista (IC). Uno de los ejemplos más claros de esta dinámica fue el giro dado por la IC que implicó el pasaje de la estrategia de "clase contra clase", adoptada por esta organización en su VI Congreso, a la política de los "Frentes Populares" implementada desde el siguiente congreso realizado en 1935. Este giro implicó un reordenamiento de las fuerzas que moldeaban la geopolitica del período, y la constitución de frentes, como los desarrollados en Francia y en España, basados en la idea de "unidad" de "todas las fuerzas democráticas" para contrarrestar el avance del fascismo. Es decir, la colaboración con unos sectores de la burguesía en oposición a otros, y por ende la idea de que obreros y burgueses podian pelear por el mismo objetivo bajo determinadas circunstancias. Todos los partidos comunistas, incluido el argentino (de ahora en más, PC), debieron reevaluar su política, repensar sus alianzas, y reorientar sus objetivos.

En este artículo nos centraremos en el impacto político del siguiente gran giro estratégico del PC, que fue la adopción de una politica neutralista frente a la segunda guerra mundial, producto del pacto sellado en agosto de 1939 entre los ministros de relaciones exteriores de la URSS y de Alemania, Viacheslav Molotov y Joachim von Ribbentrop. Buscaremos en particular observar el impacto que este viraje estratégico tuvo en el desarrollo de la política comunista en Argentina durante los meses que estuvo vigente el pacto, desde agosto de 1939 hasta junio de 1941, con la invasión de Alemania a la Unión Soviética. Para ello, pondremos el impacto sobre la relación política entre el PC y el Partido Socialista tras el cambio de estrategia, como vía para detectar continuidades y rupturas durante el periodo.

Creemos que la relevancia de abordar este período se debe a que se trata de un tema poco explorado por la historiografia dedicada a los estudios sobre el comunismo argentino ${ }^{1}$ y las izquierdas, e incluso aquellos dedicados a la historia del movimiento obrero y sus organizaciones en general. En algunos casos los trabajos que hacen mención al período lo hacen de forma tangencial, poniendo énfasis casi exclusivamente en la dimensión sindical del cambio de estrategia adoptado por los comunistas

1. Para un balance de la producción historiográfica referida al comunismo argentino, nos remitimos a Cernadas, Pittaluga y Tarcus (1998), Campione (1996), Camarero (2005). 
(Del Campo, 1983; Matsushita, 1986; Godio, 1989; Horowitz, 2001). En otros se trata de referencias en trabajos de mayor envergadura (Camarero, 2007, quien observa la inserción del comunismo en el medio social). También existen menciones en estudios abocados a analizar el impacto en el terreno intelectual o de las ideas (Barrio de Villanueva, 2001; Pasolini, 2013; Massholder, 2013; Prado Acosta, 2015; Petra, 2018). Finalmente podemos señalar aquellos referidos a la relación entre el PC y la IC (Ramos, 1962; Plá, 1987; Puiggrós, 1973; Lvovich y Fonticelli, 1999). Sobre estos trabajos, creemos necesario destacar que nuestra perspectiva se ubica en las antipodas de un mecanicismo simplista, que pretenda ver únicamente la repetición de los discursos cominternistas en el PC. Creemos que de lo que se trata, es de entender el peso de esta estrategia política en el desarrollo político del PC en esos meses.

Si la política del PC estaba fundamentada en la amenaza nazi, y en una postura de apoyo a las "fuerzas democráticas" a nivel mundial (entre las que se encontraban, desde las perspectiva comunista, Inglaterra y Estados Unidos, limitando la etiqueta de "imperialismos" a la Alemania nazi y a la Italia fascista): ¿cómo pudo adecuar su discurso político a una definición que de antemano cuestionaba el sistema de alianzas que había edificado en los últimos años? ¿Generó dificultades al PC justificar este giro? ¿En qué sentido se modificó su orientación política?

La hipótesis que guiará este artículo es que el giro neutralista del PC en 1939 tuvo un impacto político cualitativo en el desarrollo de la intervención del PC durante los meses que duró el acuerdo, en las definiciones que hacen a su caracterización de aliados, enemigos y adversarios. Al mismo tiempo, seguiremos la idea de que este giro abrió un campo de disputa político-ideológica con el Partido Socialista, que implicó un cambio de actitud respecto del periodo anterior.

Para realizar este análisis utilizaremos centralmente los órganos de prensa comunistas Orientación y La Hora, por ser sus publicaciones de mayor alcance en esos años. También recurriremos a La Vanguardia, y distintos periódicos de tirada nacional para contrastar las elaboraciones comunistas y dar cuenta de los debates que se produjeron.

Este artículo, por su punto de partida, tiene una periodización dada por el propio desarrollo de los acontecimientos internacionales y su relación con la estrategia adoptada por la URSS. Sin embargo, realizaremos un permanente contrapunto con el periodo anterior, para comprender las continuidades y rupturas en la politica comunista.

\section{Las primeras reacciones al pacto en la política argentina. El comienzo del debate}

El temor a un inminente conflicto armado a nivel internacional atra- 
vesaba, hacia mediados del año 1939, a todo el arco político nacional, y ocupaba las páginas de los periódicos argentinos. Según Domingo Varone, de origen anarquista y posteriormente militante comunista, "el ambiente público estaba cargado de combatividad. La guerra contra la Alemania de Hitler, la lucha mundial contra el fascismo, infundía espíritu de combatividad en nuestro pueblo" (Varone, 1989). Si a este clima sumamos la tensión acumulada durante los años de la Guerra Civil en España, ${ }^{2}$ entenderemos que en Argentina los acontecimientos de Europa no pasaron inadvertidos.

A nivel de sus alianzas políticas, los meses previos al pacto de la URSS con Alemania encontraron al PC desarrollando una fuerte politica de unidad sindical con las "fuerzas democráticas" (principalmente el Partido Socialista, en adelante PS). ${ }^{3}$ Tras su Congreso de 1938, la definición de unidad fue acompañada de una búsqueda por construir una hegemonía comunista en ese bloque, cuyo eje principal debía ser la oposición al fascismo. En esta búsqueda de hegemonía, el PC desarrolló dos facetas complementarias en su intervención frentista: a) por un lado, mostrar a la URSS como la verdadera vanguardia de la lucha contra el fascismo, junto con un llamado a la unidad de las fuerzas democráticas, pero haciendo hincapié en las políticas de "apaciguamiento" y "temor", sobre todo dirigidas al primer ministro británico Neville Chamberlain; b) por otro, como se expresó en el Primer Congreso Ordinario de la CGT, tras la incorporación de la Federación Obrera Nacional de la Construcción (FONC) ${ }^{4}$ en julio de 1939, el PC se fue transformando en el abanderado de la unidad, planteando un escenario idílico de armonía entre las fuerzas que se enfrentaban al fascismo y en donde el "divisionismo" era el principal enemigo (mayormente representado, según la prensa comunista, por los grupos trotskistas o por supuestos grupos fascistas infiltrados en el movimiento obrero).

Lo que intentaremos rastrear en esta primera parte de nuestro trabajo es el impacto del giro neutralista tanto en estas definiciones estratégicas que encauzaban la política comunista hasta semanas y dias antes del 23 de agosto de 1939, como en las organizaciones políticas adversarias del PC, que tomaron este giro como una traición a la línea unitaria que estos venían desarrollando.

2. Para una revisión más general sobre el impacto de la Guerra Civil en la Argentina nos remitimos a los trabajos de Goldar (1986), Quijada (1991), Montenegro (2005) y Cattaruzza (2005).

3. Sobre el Partido Socialista durante este período ver Camarero y Herrera (2005).

4. Vale destacar que la FONC representaba un emblema para el comunismo y su inserción en el movimiento obrero, en tanto era un ejemplo de su idea de sindicatos únicos por rama industrial. Ver Camarero (2012) y Ceruso (2010). 
Alfredo Palacios, en una columna de La Vanguardia, decía pocos días después del pacto, que "no existe en la historia ejemplo de un cinismo tal como el que han demostrado los dos dictadores de los regimenes totalitarios", ${ }^{5}$ en abierto contraste con las esperanzas del mismo periódico dias anteriores, en donde se anunciaba el avance de las negociaciones entre Francia, Gran Bretaña y la URSS. A la izquierda del PC, Mateo Fossa, militante trotskista y dirigente obrero reconocido por su rol en el sindicato de la madera, destacaba también la ruptura en el discurso del PC y sus repercusiones: "Lacayos y esbirros a sueldo, ahora tendréis que cambiar de disco y de librea, pues vuestro amo ha pactado con el "“único enemigo", el fascismo". ${ }^{6}$ Incluso a nivel nacional, en periódicos de tirada masiva como El Litoral de Santa Fe, no se obvió el paradójico acuerdo, señalando que "Rusia y Alemania que vivieron llenas de odio, ahora podrán convivir, y hasta presenciar la lucha entre otros países sin atacarse". ${ }^{7}$ La primera plana de La Prensa, también amaneció el 24 de agosto con la noticia: "Los señores Von Ribbentrop y Molotoff firmaron en Moscú el pacto de no agresión". ${ }^{8}$ También en sus páginas centrales La Prensa, destacaba "el hondo impacto en la opinión pública francesa" que había provocado la firma del pacto.

Asimismo, el hecho causó revuelo en el mundo intelectual sobre el que los comunistas argentinos intervenían. En este sentido la editorial del mes de octubre de la revista Claridad (que adquiriria una gran influencia entre la intelectualidad de izquierda de la época), dedicada a un análisis del pacto, sentenciaba que Stalin se había consagrado como el "campeón de las traiciones". ${ }^{9}$

Es decir, prácticamente ningún actor político con los que el PC compartía espacios de intervención o espacios políticos en general se mantuvieron indiferentes al hecho. ¿Pero cómo reaccionaron los propios comunistas? Tanto en elaboraciones posteriores, como en las publicaciones del momento, se pueden detectar las dificultades que tuvo el PC para articular un relato coherente, sin reconocer contradicciones. En relatos con mayor distancia temporal en relación a los hechos, como el Esbozo de la historia del Partido Comunista de Argentina, (1947) o en la oficialista Historia del Partido Comunista, de Oscar Arévalo (1983),

5.“Una sensación de estupor”, La Vanguardia, 2 de septiembre de 1939.

6. "Escribe Mateo Fossa sobre el pacto Nazi-Stalinista", La Internacional, órgano del Grupo Obrero Revolucionario, septiembre de 1939.

7. "El pacto Ruso-Germano, no está basado en afinidades ideológicas, sino en la ley de la necesidad", El Litoral, 24 de agosto de 1939.

8. "Los señores Von Ribbentrop y Molotoff firmaron en Moscú el pacto de no agresión", La Prensa, 24 de agosto de 1939.

9."Editorial”, Claridad, 10 de agosto de 1939. 
prácticamente no se hace mención al asunto, estableciendo una continuidad entre las discusiones abiertas por el IX Congreso de 1938 y el siguiente, en el año 1941, que coincide temporalmente con la vuelta de Victorio Codovilla y Rodolfo Ghioldi al país. Un trabajo bastante posterior, de Isidoro Gilbert sobre la Federación Juvenil Comunista, corriente de la cual el autor fue parte, se corre brevemente del relato oficial de aquel entonces, apuntando que "el mariscal Stalin, había firmado en 1939 un pacto de no agresión con Hitler, más para ganar tiempo en el enfrentamiento que sabía inevitable, que para convertir al convenio en un instrumento de paz entre el Oeste y el Este" (Gilbert, 2009: 192).

Volviendo al eje sincrónico, ya desde el momento mismo del pacto la prensa comunista tuvo que clarificar el contenido del giro para propios y ajenos. En su nota de portada del día 24 de agosto, Orientación daba cuenta de la necesidad de responder a las repercusiones de la noticia y de contener la posible confusión que se pudiera presentar en una base amplia de su partido (al menos los lectores de Orientación). En ella advierte sobre la necesidad de dar una "lucha verdadera y resuelta contra los capituladores" que "quieren cegar la opinión pública". ${ }^{10}$

Podriamos definir que la primera reacción de la prensa comunista a las críticas fue mostrar el acuerdo como un triunfo. Si tenemos en cuenta las extensas negociaciones entre Francia, Inglaterra y Rusia durante los meses anteriores a la guerra, y las posteriores críticas comunistas al acuerdo de Múnich en 1938, entenderemos que para la diplomacia soviética la firma del tratado con Alemania no podía ser presentada como una sumisión o como un intento de anexión de Polonia. En aquel entonces, la aceptación por parte de Francia e Inglaterra de que Alemania anexara los territorios checoslovacos fue considerada por los comunistas como un complot de los países occidentales para aislar a la Unión Soviética. Pero en 1939 la situación cambió: fueron los comunistas los protagonistas del acuerdo de paz, lo cual se interpretó como una reversión exitosa del fracasado acuerdo de Munich. En este sentido, el PC se limitó a reproducir los principales comunicados de Molotov y las editoriales del Pravda, en donde se consideraba la firma del acuerdo de no agresión como un gran "suspiro de alivio" para toda Europa y como una "garantía de paz" para toda la humanidad. Orientación, en el primer número tras la firma del pacto, anunciaba que "La política exterior de la URSS tiene un objetivo supremo: La Paz mundial". ${ }^{11}$ En la misma

10."Lucha verdadera y resuelta contra el fascismo. Lucha verdadera y resuelta contra los capituladores. Los responsables de Múnich quieren cegar a la opinión pública”, Orientación, 31 de agosto de 1939.

11."La política exterior de la URSS tiene un objetivo supremo: La Paz mundial", Orientación, 24 de agosto de 1939. 
dirección se expresó quien fue un aliado del PC durante todo este período, Benito Marianetti, dirigente del Partido Socialista Obrero (PSO), que definió al pacto como "un gran triunfo diplomático de la URSS". ${ }^{12}$

Sin embargo, el alboroto generado no detuvo su intensidad por mostrar un triunfo, ya que lo que estaba en cuestión eran los medios por los que se había llegado hasta alli. Por eso la siguiente reacción que tuvo el PC fue buscar encastrar su decisión en el corpus teórico comunista.

El secretario general del PC Arnedo Álvarez fue uno de los primeros en abordar el pacto desde esta perspectiva, destacando que sólo "a la luz del marxismo leninismo se debe comprender el pacto"13 y apelando a la analogía histórica. El argumento de Âlvarez es el siguiente: quienes en otros tiempos acusaron de traición a Lenin por el pacto de Brest-Litovsk, son los mismos que hoy acusan a Stalin de "venderse" a Hitler, con el solo fin de "aislar a la URSS de la simpatía mundial". Es decir, una especie de comparación transversal en donde Stalin sería Lenin y donde el preámbulo de la Segunda Guerra Mundial se equipara con las negociaciones de Brest-Litovsk.

A esta idea se sumaba la reafirmación del carácter de la URSS como un estado incomparable con el fascismo. Si bien las analogías por parte de los críticos de la URSS, que tendian a igualar a ambos regímenes bajo el rótulo de "totalitarios", son previas a la firma del pacto, el acercamiento diplomático entre ambas potencias las puso en el centro de la escena. Así, tras varias semanas publicando artículos en la misma dirección, el 28 de septiembre, encontramos una página completa de Orientación con el título “¿Fascismo = comunismo?" ${ }^{14}$ En todo el espacio de la página se van destacando items como cultura, ciencias, derechos sindicales, y por supuesto el rol de ambos respecto de la guerra, en donde se resaltan las virtudes del estado soviético, y se establece una suerte de "maniqueísmo extremo" en relación a la Alemania nazi.

Finalmente, detectamos que ya desde los primeros dias tras el pacto comienza una serie de polémicas entre el PC y los socialistas, que atravesaría todo el período, y que marcaría fuertemente el discurso de la prensa comunista durante los meses que duró el pacto.

Los socialistas de La Vanguardia, en la edición del 24 de agosto, dieron comienzo en sus páginas al "Debate libre" sobre el pacto HitlerStalin, el cual se transformó en una sección permanente de su periódico durante las siguientes semanas. Alli escribieron socialistas, trotskistas,

12. El pacto germano soviético, Conferencia Pronunciada por Benito Marianetti en la casa de los trabajadores de Mendoza la noche del 30 de agosto de 1939 (folleto).

13. "Es a la luz de la teoría marxista leninista que debe verse el pacto", Orientación, 31 de agosto de 1939.

14. “¿Fascismo = comunismo?”, Orientación, 28 de septiembre de 1939. 
liberales y hasta los propios comunistas, en una especie de "derecho a réplica". Ya desde su anuncio, en la primera plana de La Vanguardia, un gráfico muy sugestivo superpone una esvástica con una hoz y un martillo, dando cuenta de la linea que editorializaria el "debate libre": considerar al pacto como una alianza entre ambos regimenes totalitarios y calificar a los comunistas de traidores. ${ }^{15}$

La reacción de los comunistas a las críticas también fue inmediata, alarmados por la confusión que pudiese generar ese "debate libre". Orientación publicó un extenso artículo cuyo título graficaba lo que acabamos de relatar: "Algunos socialistas tergiversan el sentido del pacto soviético-germano", ${ }^{16}$ en donde planteaba: "¿Cómo es posible, compañero de La Vanguardia, que ustedes hayan dado crédito a las deformaciones que las agencias de Chamberlain y Daladier propalaron sobre el pacto germano ruso?". Y continúa:

Enrique Dickmann ha reconocido el argumento banal sobre los puntos de contacto entre sovietismo y hitlerismo [...] Romulo Bogliolo, insinúa que tal vez la URSS quiera tragarse a los débiles vecinos y la critica porque su diplomacia mantiene relaciones con los países fascistas. Son regocijantes los escrúpulos de este socialista que ha justificado los compromisos más podridos cuando ellos iban contra los intereses del proletariado, y no comprende o no quiere comprender que el estado soviético, como condición para su existencia, debe mantener relaciones con todos los estados del mundo, prescindiendo de su régimen interno. ${ }^{17}$

Pero sería limitado quedarnos con la idea de que se abre un periodo de ruptura terminante entre socialistas y comunistas a partir de estas primeras rispideces que expresa el pacto. La realidad fue otra. Y será uno de los hilos que nos conducirán a entender las contradicciones más profundas que expresa el pacto en el accionar de los comunistas durante los meses siguientes. Para ser más claros, limitémonos a observar cómo concluye una nota de tono polémico:

Ningún insulto nos hará perder la serenidad. Para nosotros

15. Vale aclarar que aunque en este artículo haremos referencia al período neutralista y a la coyuntura que comienza en 1939, algunas de estas caracterizaciones y tensiones entre socialistas y comunistas, pero también al interior de propio partido socialista y en las izquierdas en general, son previas. Ver Bisso (2005), Pasolini (2013). 16. "Algunos socialistas tergiversan el sentido del pacto soviético-germano", Orientación, 31 de agosto de 1939.

17. Ídem 
lo más grave de los artículos de La Vanguardia es que abren -alentados por los provocadores trotskistas- una brecha en la unidad de acción. De nuestra parte, hoy como ayer más que ayer, seguiremos trabajando por la unidad de acción socialista comunista por objetivos comunes y contra enemigos comunes. Intensificaremos en las fábricas, en los sindicatos, en todas partes nuestro acercamiento a los compañeros socialistas para organizar al proletariado argentino y para robustecer el movimiento sindical. ${ }^{18}$

Es decir, pese a las acusaciones de calumnias, de trabajar para el imperialismo francés e inglés y de confundir el pacto con una traición, "lo más grave" para los comunistas, tomando la expresión de su artículo, era la ruptura en la unidad de acción con los socialistas. Pero al mismo tiempo advertian: esa gravedad cobraba importancia, no por las acusaciones morales mantenidas con la dirigencia socialista que escribe La Vanguardia, sino por lo que sucede en las fábricas, en los sindicatos, en aquellos lugares donde el contacto entre ambas fuerzas era cotidiano, palpable, donde los epitetos y adjetivos impactaban sobre personas de carne y hueso.

La relevancia de esta advertencia es fundamental ya que da cuenta del impacto en la práctica comunista de un giro que podríamos denominar "exógeno" en relación al "movimiento natural" del partido en los años y meses anteriores, que lo había acercado en la cotidianeidad al Partido Socialista y a sus simpatizantes. La noticia del pacto y de los nuevos realineamientos, además de inesperada, actuó como una fuerza fantasmal sobre el timón del PC, que lo obligó a señalar una dirección cuando el barco aún estaba virando en sentido opuesto. O en otros términos: la IC impuso un giro brusco a la orientación del PC local que debió revisar todos los aspectos de su política para adecuarse a los lineamientos del Kremlin.

Para observar la forma en que impacta el viraje en el periodo posterior, creemos pertinente detenernos en los cambios de actitud de la prensa comunista hacia el PS y de qué manera los cambios en la propia guerra alteran la relación entre quienes durante el período previo estaban avanzando hacia consolidar alianzas politicas y sindicales.

\section{El debate con el socialismo y la profundización del giro}

Ya hemos analizado las primeras reacciones ante al pacto que mar-

18. "Más que nunca, pese a los provocadores se impone la acción común SocialistaComunista", Orientación, 7 de septiembre de 1939. 
can las tendencias del período y detectado cómo el viraje se produce inmediatamente tras la firma del pacto Molotov-Ribbentrop. Pero añadiremos que la instancia de mayor recrudecimiento del giro neutralista y antialiado será mayo de 1940. ¿Por qué mayo? Porque es el momento de mayor ofensiva de las tropas alemanas tras sus triunfos en el norte europeo, y por ende el momento de mayor temor por parte de los aliados a una ofensiva exitosa del Eje.

Efectivamente los socialistas, a partir de esta fecha, aumentaron su retórica proaliada. Lo que hasta el momento era una hipótesis, en mayo de 1940 se transformó en una amenaza real y creciente a la "democracia occidental". No es casualidad entonces que a partir de esos meses hayan aumentado las rivalidades previas en la CGT. ${ }^{19}$ Tampoco lo es que durante el mes de mayo de 1940 el PS haya comenzado las tratativas con personalidades de la cultura y otros partidos politicos para poner en pie, el 5 de junio, Acción Argentina, ${ }^{20}$ un grupo destinado a promover el apoyo argentino al bando aliado.

Según Pasolini, la aparición de Acción Argentina en el escenario nacional inicia una etapa de disputa entre los grupos antifascistas. Para este autor, la nueva percepción de los comunistas sobre los aliados, como meros defensores de sus intereses imperialistas, generó una oposición entre la Agrupación de Intelectuales, Artistas, Periodistas y Escritores (AIAPE) ${ }^{21}$ que nucleaba a los intelectuales cercanos al comunismo, y Acción Argentina, que es descripta por Pasolini como "una organización que agrupaba a no pocos políticos e intelectuales de tradición liberal y socialista, cuya prédica tenía un fuerte componente anticomunista, en la medida en que luego del pacto germano soviético, se reactivó el supuesto de una identidad totalitaria entre comunismo y nazismo, excluyendo de este modo a los comunistas de la alianza antifascista local" (Pasolini, 2013: 104)

Es decir, a partir de mayo de 1940 se da un doble movimiento que alejó aún más a socialistas y comunistas.

Por un lado, los socialistas reforzaron su apoyo al bando aliado, amenazado directamente por el fascismo alemán. Para ello recurrieron

19. Aunque el debate entre socialistas y comunistas al interior de la central se recrudece con la firma del pacto, Matsushita señala cómo en estos meses de 1940 se da una escalada: se separa a Andrés Roca y Carlos Pérez, ambos de la FONC, del C.A de la CGT, y luego a José Peter, histórico dirigente comunista, y por ese entonces representante del gremio de la alimentación.

20. Para una visión más general sobre esta organización nos remitimos al trabajo de Bisso (2005).

21. Para una visión general sobre esta organización durante el período nos remitimos a Cane (1997), además de los trabajos ya mencionados de Pasolini. 
a nuevos aliados con los cuales pusieron en pie Acción Argentina y buscaron apropiarse a nivel masivo de la bandera anti fascista, distanciándose del anti fascismo comunista. Muchos de esos aliados eran denunciados por los comunistas como representantes de la Argentina oligárquica y fraudulenta (justistas, alvearistas, etc.) y varios de ellos eran abiertamente anticomunistas. La idea de un Frente Popular integrado por socialistas y comunistas, democrático, nacional, antioligárquico, era una perspectiva cada vez más irrealizable.

En paralelo, en el movimiento obrero, este corrimiento hacia una actitud más abiertamente pro aliada supuso un acercamiento entre el grupo socialista de la CGT y José Domenech, ${ }^{22}$ llegando al punto de aprobar una declaración que fijaba una línea proaliada desde la central, pese a la extrema cautela de sus dirigentes para pronunciarse sobre los "asuntos políticos". ${ }^{23}$

Por su parte el PC reforzó la relación entre antifascismo y la defensa de la URSS, alejándose del antifascismo proaliado. A nivel local, el avance de Alemania obligó a muchos sectores que se reivindicaban neutrales, pero que guardaban simpatías con Francia e Inglaterra, a hacer aún más explicitas sus simpatías con los aliados, y hasta a pronunciarse por el apoyo argentino contra la avanzada fascista. Esto fue interpretado por los comunistas como una posibilidad real de que Argentina se incorpore a la guerra y por ende como una oposición aun mayor a su neutralismo. Para el PC, la bandera del antifascismo neutral se volvió una causa que contaba cada vez con menos adeptos. A nivel de su disputa con los socialistas en la CGT, esta situación se convirtió para los comunistas en un retroceso dentro de la central, ya que además de implicar la expulsión de importantes dirigentes obreros comunistas de los órganos directivos, ante la avanzada del grupo socialista en alianza con Domenech, supuso la necesidad de recurrir a antiguos aliados, como la USA, para evitar el completo aislamiento político (Matsushita, 1986: 229).

En un artículo de Orientación de junio de 1940 en polémica con Enrique Dickmann y Joaquín Coca, Ernesto Giudici explicitó este alejamiento confirmando el peso de la dinámica bélica: "Los que ayer éramos amigos hoy somos nazi comunistas". Y a continuación se preguntaba

22. José Domenech era en aquel entonces el secretario general de la Unión Ferroviaria.

23. Matsushita relata los constantes esfuerzos, sobre todo de la Unión Ferroviaria, por evitar los pronunciamientos a favor o en contra de alguno de los bandos en guerra. Sin embargo, señala que "tal llamado a la prescindencia respecto del problema internacional no llegó a ser cumplido. Una razón fue que el problema internacional estaba estrechamente ligado a los intereses obreros". Y agrega: "En especial, en el caso de los ferroviarios, la continuidad del régimen del laudo se convirtió en un problema más serio durante la guerra" (Matsushita, 1986: 224). 
qué fue lo ocurrió en el país para que se produjera ese cambio: "Nada, lo que cambió fue la guerra en Europa". ${ }^{24}$

Este impacto lo vemos en el cambio de actitud de los comunistas en sus propios periódicos. Si en septiembre de 1939 Orientación planteaba en un tono de expectativa y diálogo extremadamente mesurado que "La Vanguardia puede aún salir del pantano", el giro de mayo ya lo ubicaba completamente hundido en él. La primera diferenciación que debió hacer el PC era entre su antifascismo y el de Acción Argentina. Por eso, ya en mayo La Hora se encargó de señalar las contradicciones del antifascismo socialista: "Los socialistas repiten hoy las calumnias de la guerra pasada. Pero la historia ha dado ya su veredicto: de la guerra pasada no surgió la democracia por la cual los dirigentes socialistas mandaron tantos hombres a la muerte, sino que surgió el fascismo". ${ }^{25}$ Para el PC, el pasado de los socialistas los condenaba a un antifascismo ficcional, que al disputar con los alemanes en el mismo terreno de la puja imperialista sólo lograba fortalecerlo, en tanto no cuestionaba sus raíces profundas.

Solo días después de su formación, se publicó en La Hora una respuesta al primer comunicado de Acción Argentina, que señalaba una ruptura doctrinaria y un salto en la posición socialista. En ella se afirmaba que

la declaración del PS, enfoca el problema de la guerra desde un ángulo que nada tiene que ver con la doctrina y los principios del socialismo científico. Atribuye toda la responsabilidad de la tragedia horrorosa que se ha desatado sobre los pueblos del mundo, a los países totalitarios. Pasamos por alto la deliberada confusión que se introduce mediante la utilización anfibológica del término totalitario, destinado a igualar la amplia y genuina democracia socialista soviética, con el régimen de dictadura sanguinaria. ${ }^{26}$

A continuación La Hora se preguntaba sobre las causas de este giro brusco de los socialistas. Y encontraba una explicación funcional: el cambio no se debió solo a lo acontecido en Europa, sino que se trató de una posición ya existente pero disimulada por temor a la reacción de

24. "Del Contubernio a la Quinta Columna. O Coca y Dickmann, dos ideólogos", Orientación, 2 de junio de 1940.

25. "Socialistas que están por la Guerra", La Hora, 21 de mayo de 1940

26. "El Comité Ejecutivo del Partido Socialista y la actual guerra.", La Hora, 30 de mayo de 1940. 
los trabajadores. Los socialistas habian esperado el momento oportuno, el avance del fascismo, para hacer explícita su posición:

durante la campaña electoral, ningún orador socialista se refirió al problema de la guerra, a pesar de ser el más terrible problema del momento. Y no se referian a él, pues temian que una posición a favor de uno de los bandos provocase un desastre en los resultados electorales. ${ }^{27}$

El PC mostraba que la bandera unitaria que levantaban los socialistas era parte de esta estrategia: “¿Unidad nacional para qué? ¿Para llevar el país a la guerra?”. ${ }^{28} \mathrm{Y}$ el argumento que mejor servía a los comunistas para ejemplificar esta impostura era el tendido amplio de proaliados que ahora encabezaban los socialistas:

Ahora, autoriza a sus más destacados militantes, como a Nicolás Repetto, a participar en un dudoso "Comité de acción" al lado de Sylla Monsegur y de González Roura, para ayudar al imperialismo anglo-francés. Estas declaraciones no pasarán inadvertidas para los ciudadanos argentinos a quienes se dirige la declaración de marras. ${ }^{29}$

Para los comunistas, la unidad nacional que pregonaban los socialistas era una traición. Era una unidad nacional espuria con los principales enemigos de la patria. La alianza entre los socialistas y sectores de la oligarquía fue leída como un intento de garantizar, a través de esa confluencia circunstancial de intereses, el comercio con Inglaterra. Así también se expresó en el movimiento obrero. Matsushita señala, por ejemplo, que el discurso de Domenech pronunciado en un mitin de Acción Argentina, en favor de los aliados, fue interpretado por el PC como una renuncia a la lucha contra el laudo, que implicaba enfrentarse a los capitales ingleses, y por lo tanto era calificada como "traidora, mil veces traidora, traidora a la clase obrera, traidora a la Nación Argentina, traidora a la causa de la democracia". ${ }^{30}$ Sin embargo, el punto más alto de la "traición" llegó en el momento en que socialistas, sectores radicales, demócrata progresistas y distintos representantes de los terratenientes votaron la Ley de Emergencia. Más allá de las implicancias represivas

27. Ídem.

28. Ídem.

29. Ídem.

30. Citado en Matsushita (1986: 225). 
que tenía para los comunistas esta ley, ${ }^{31}$ en principio estaba destinada a reconocer el impacto de la guerra y a evitar los obstáculos de las relaciones comerciales con Europa.

En este sentido los comunistas intentaron asociar la politica de Acción Argentina con su carácter de clase. La Hora señalaba que en aquella alianza solo están representados los sectores oligárquicos, que "pueden pagar anuncios en las páginas de los diarios más caros del país"; y denuncia:

¡No hay en ella ni un solo nombre de un dirigente obrero! ¿Así que el doctor César Blaye presidente de la Defensa Anti social es anti fascista? ¿Lo es también por acaso el eminente presidente de la sociedad rural, Dr. Adolfo Bioy? ¿Han olvidado el uno su admiración y el otro su colaboración con el general Uriburu, introductor y propulsor máximo de las actividades fascistas en nuestro país? ${ }^{32}$

Sin embargo los comunistas debieron dar cuenta de la popularidad que había logrado el comité de Acción Argentina ¿Cómo tantos trabajadores honestos se habian dejado engañar por unos pocos dirigentes? Para eso la explicación fue simple: habían recurrido a la demagogia. Habian apelado al verdadero sentimiento de las masas contra el imperialismo alemán y el fascismo, y se habian apoyado falsamente, al plantarse como abanderados de la unidad nacional y como los representantes de "lo argentino", en el sentimiento antibritánico. Por ende este debate con Acción Argentina nos da la idea de que la postura del PC, pese a que lo aísla relativamente del sistema de alianzas con los partidos del régimen, no necesariamente lo hace con el sentimiento de "las masas". Sería muy dificil, como ya señalamos, tener retrospectivamente una percepción real sobre la simpatía, a nivel "de masas", con Alemania y con Inglaterra. Pero lo que queda claro es que ambos antifascismos, el

31. Sería tema de futuras investigaciones estudiar la relación entre comunismo y represión en este período, y en especial alrededor de las medidas tomadas por el gobierno nacional, ante el escenario bélico mundial. Pero vale mencionar que son los propios comunistas, pese a su aceptación discursiva del régimen político bajo el gobierno de Ortiz, los que denuncian permanentemente esta avanzada represiva. Por ejemplo, el 3 de junio de 1940, La Hora denuncia que la Ley de Emergencia votada por el Ejecutivo nacional era un "virtual estado de sitio", hasta que finalice la Guerra y agregaba: "Se dice que es para defender la neutralidad. Y resulta que esta Ley de Emergencia, dirigirá su filo contra los verdaderos neutralistas, que no son los partidarios de los nazis ni son los partidarios del imperialismo Inglés" (La Hora, 3 de junio de 1940).

32. "Olvidándose de la clase obrera, el diputado socialista Ghioldi obtuvo el aplauso de la reacción", La Hora, 9 de junio de 1940. 
del PC de forma explícita y el de Acción Argentina, se mostraron alejados de los intereses extranjeros. Es decir, podemos afirmar que más allá del éxito de cada una de las estrategias, hay un espacio de disputa por una especie de "lugar común", que es el nacionalismo de distinto tipo. ${ }^{33}$

Asimismo, lo que notamos como continuidad en la política comunista es el intento por dialogar con la base socialista, distinguiéndola claramente de las decisiones antipáticas de su dirección. La advertencia sobre las consecuencias del apoyo a los aliados puede reforzar la hipótesis de que existió un sector en disputa sobre el cual el PC quiso influir bajo la idea de que el rumbo aliadófilo era una desviación de los principios socialistas y una "traición" a sus bases. La Hora incluso sentenciaba que "los socialistas se apartan día a día de la masa popular" ${ }^{34}$ Esto permitió a los comunistas pasar a la ofensiva: "Somos traidores, sí. Pero, ¿a quién? Traidores nos puede llamar el imperialismo Inglés, el imperialismo Alemán, y todos los imperialismos". ${ }^{35}$ La diferenciación entre la dirección socialista y sus simpatizantes por parte del PC recurrió al ya mencionado discurso de la unidad:

Ustedes, Alvear, Repetto, Noble, nos proponen la guerra. Nosotros les proponemos la Paz interior, es decir la conciliación interna, la unidad de los partidos, la unidad nacional contra el imperialismo. ¿Por qué no aceptan ésta que está más cerca de nosotros, que es más fiable, más sólida, más sana? [...] Porque ustedes juegan con los sentimientos de las masas. ${ }^{36}$

La posición de los comunistas pasó a autoidentificarse como la "tercera posición". ${ }^{37} \mathrm{Ni}$ aliadófilos ni germanófilos: nacionalistas socialistas antiimperialistas. La pretensión al hacer esta distinción era convencer a aquellos que se sentían identificados con una "verdadera neutralidad", es decir una no beligerancia activa, de que los dirigentes socialistas los estaban llevando detrás de los intereses del imperialismo, y por ende de la oligarquía "antipatria". Uno de los testimonios más interesantes en este sentido nos lo brinda La Hora, en una nota titulada "Palabras

33. En este sentido, no es casualidad que varios autores resalten las semejanzas entre varios de los planteos del PC y grupos como FORJA, y uno de sus principales referentes, Scalabrini Ortiz.

34. "Socialistas que están por la Guerra", La Hora, 21 de mayo de 1940.

35. Ídem.

36. "La Unidad Obrera y democrática, no la Guerra, salvara al País", La Hora, 22 de mayo de 1940.

37. Encontramos por primera vez esta definición el 22 de mayo en La Hora, en un artículo que lleva el mismo título. 
imprudentes de un militante obrero", que presenta una polémica (presuponemos que ficcional, pero verosímil) entre un militante comunista y un obrero ferroviario que apoyaba a Acción Argentina. El obrero comunista pone contra las cuerdas a su adversario:

El manifiesto del presunto comité de acción niega que exista una lucha por la hegemonía entre dos imperialismos. Existe solamente un imperialismo, el nazi, que es el único que nos amenaza. [...] Pero este obrero ferroviario, no pudiendo negar la existencia del imperialismo inglés, declara su preferencia de ser esclavo de él, antes que esclavo del imperialismo alemán.

Y agregaba, dándole una salida ante la traición de su dirección, que

En esta guerra no existen dos frentes, sino tres. Un frente es el nazi, el otro es el anglo-francés. Pero el tercer frente es el que han levantado los obreros de todo el mundo, los pueblos oprimidos, los campesinos, los hombres de bien, los intelectuales honestos, para terminar de una vez con las causas que generan las guerras de conquista y rapiña. ${ }^{38}$

Es decir, la idea de "tercera posición" no era solo auto identificadora, sino también una forma de tender un puente entre los comunistas y las bases socialistas que podian haber visto con malos ojos la formación de Acción Argentina. Una pregunta que vuelve a aparecer es efectivamente cual era el "sentir" del movimiento obrero frente a la guerra. Escapa a los limites de este trabajo dar una respuesta, que por otra parte implicaría establecer un método que considere un recorte de clase. Sin embargo, vale señalar que hay una coincidencia en varios autores (Del Campo, 1983; Godio, 1989; Matsushita, 1986; Horowitz, 2001), entre los que se destaca Matsushita por la profundidad de su análisis, en afirmar que la guerra, ya desde sus comienzos, implicó cimbronazos para la economía popular. No casualmente tanto en La Hora como en Orientación aparecen permanentes referencias a los padecimientos de la clase obrera producto de la guerra. Y tampoco resulta aleatorio que este tópico se haya transformado en un argumento en la polémica con los socialistas.

Creemos que esta actitud más ofensiva hacia la militancia socialista tuvo un salto en noviembre de 1940, tras el congreso del PS. Alli el PC ajustó su definición sobre el rol específico de la clase obrera para su estrategia, alejándose aún más de los socialistas, a quienes caracterizaban como un partido cada vez menos involucrado con el proletariado

38. "Palabras imprudentes de un militante obrero", La Hora, 30 de mayo de 1940. 
argentino. La visión del congreso del PS fue extremadamente negativa: "Interesó más el triunfo de las armas británicas y la entrada de Estados Unidos en la guerra que nuestros conflictos obreros y la lucha que en estos momentos realizan diversos sectores de la población contra la opresión imperialista oligárquica". ${ }^{39}$

Como hemos dicho más arriba, la política de Frente Popular que proponía el PC implicó darle un rol difuso a la clase obrera, o para ser más claros: un rol subordinado a que la burguesía local tomara la iniciativa revolucionaria. Sin embargo, luego del congreso del PS notamos un ajuste de esta visión por parte del secretario general del PC, Arnedo Álvarez. Citamos en extenso su definición porque creemos que es clarificadora:

El partido debe luchar por organizar un gran bloque nacional, anti guerrero, anti imperialista, anti fascista, en el que deben entrar todos los sectores objetivamente en pugna con el imperialismo. Pero no por temor de ahuyentar a la burguesía deja de proclamar que por lo mismo que lucha por integrar ese bloque en nombre de los intereses de la nación, es decir, de las amplias masas, lucha también porque ese bloque sea dirigido por el proletariado, la clase consecuentemente nacional. [...] Es una cuestión que conviene recordar. No siempre el partido supo interpretar esta politica independiente ni jugar su verdadero rol dirigente. La justa politica de lucha por la unidad y por rodear al proletariado de sus aliados lo ha conducido también a posiciones erróneas, seguidistas, a la falta de critica a posiciones equivocadas de los aliados, cayendo muchas veces en el oportunismo. Las profundas experiencias y las grandes enseñanzas del último congreso del Partido Comunista Mexicano y del Pleno del C. Central del Partido Comunista de Chile, ${ }^{40}$ deben ser recogidas por nuestro partido, y a su luz examinar audazmente las de nuestro partido para adoptar una justa linea politica. ${ }^{41}$

39. "Miró a Londres y no al País el congreso del partido socialista.", Orientación, 7 de noviembre de 1940.

40.Queremos resaltar que distintos autores han hecho referencia al año 1940 como un momento de "crisis" para los partidos comunistas de estos países, en relación a su política de Frente Popular. En el caso de Chile, donde el Partido Comunista había ganado un gran peso superestructural en su alianza con los socialistas chilenos, el giro neutralista de la IC significa una intensificación de los conflictos al interior del Frente Popular que va a desembocar en su ruptura en 1941. En el caso mexicano, también el congreso de 1940 es visto como un quiebre respecto de su relación con el gobierno de Lázaro Cárdenas. Algunos autores señalan que este quiebre se debió tanto a causas externas (el giro de la IC) como al terremoto al interior del Partido Comunista Mexicano que supuso el asesinato de Trotsky.

41. "El papel del Partido Comunista como destacamento de vanguardia del proleta- 
Es decir, no abandona la definición sobre el Frente Popular, pero dictamina que el partido no supo hacer política en su interior, que los "temores" a romper esas alianzas lo llevaron a una politica seguidista. Y la solución es volver a la clase obrera, ganarla para que pueda jugar un rol hegemónico, en tanto clase consecuentemente nacional. Creemos que en este sentido se trata de un salto: el PC ya no esperaría un giro del PS que llevase a ambos partidos a una confluencia. En su esquema de alianzas sigue estando incorporado como un potencial aliado pero el aislamiento y la lucha politica con los belicistas no sería algo negativo, sino reivindicable y necesario. La caracterización del PC es que no solo el socialismo argentino sino la socialdemocracia mundial estaba entrando en un periodo de "bancarrota", ${ }^{42}$ de crisis tras su apoyo a los aliados. ¿No sería una hipótesis entonces para el PC que la política que Álvarez llama "seguidista" sea un obstáculo para capitalizar esta crisis del PS? Es posible considerar que tras el congreso del PS, y ya en el final de la etapa neutralista, el PC endureció su crítica a los ex aliados, y transformó su posición originalmente defensiva, prounitaria, en una posición ofensiva en busca de hacer mella tras el giro del PS.

\section{Conclusión}

A modo de síntesis, podemos decir que efectivamente la relación con los socialistas tiene un punto de quiebre a partir del pacto. Pero también afirmamos que sería muy parcial quedarnos en los primeros debates originados por el pacto en sí, u observar las polémicas entre ambos grupos sólo desde las repercusiones del mismo. Más bien, para entender las discontinuidades, debemos prestar atención a la evolución de ambos grupos durante estos meses y a la evolución de la guerra en particular, que en 1940 se transforma en el foco de atención de los antifascistas locales, sean neutralistas o aliadófilos. La conformación de Acción Argentina como reacción a la avanzada alemana efectivamente significó un salto en el alejamiento de socialistas y comunistas, no tanto por la evolución de una posición más intransigente del $\mathrm{PC}$ respecto del apoyo a los aliados, sino por la configuración de un nuevo esquema de alianzas por parte de los socialistas que excluía definitivamente al comunismo. No solo por ser una fuerza que contaba con elementos anticomunistas en su interior, sino porque suponía una hegemonía socialista con apoyo de sectores de la oligarquía, en donde poco cabían los llamados del PC a una unidad nacional, con el proletariado a la cabeza de un frente

riado argentino", Orientación, 5 de diciembre de 1940.

42. "Miró a Londres y no al País el congreso del partido socialista.", Orientación, 7 de noviembre de 1940. 
antiimperialista, antioligárquico, antiguerrero y neutralista. Sin embargo, como hemos señalado, este alejamiento respecto de la estructura partidaria del PS no significó la anulación de las líneas de diálogo, que continuaron durante todo el período con los simpatizantes socialistas, a los que se eximió en el discurso comunista de las duras críticas hacia el partido de Justo.

Así como el giro en la política comunista tras la firma del pacto fue extremadamente rápido, también lo fue el ingreso a una línea belicista tras el ataque de Alemania a la URSS en junio de 1941 y la ruptura del pacto de neutralidad. En pocos dias, franceses e ingleses volvieron a ser guardianes de la libertad y la democracia, contra la bestia hitlerista. Sin embargo será motivo de futuras investigaciones detectar qué elementos del periodo neutralista se mantuvieron vigentes.

Lo que aquí queremos resaltar es que el giro dado por la IC en agosto de 1939 abrió una etapa particular en el desarrollo del Partido Comunista Argentino. Y que esta etapa presenta algunas trasformaciones cualitativas en varios niveles de su intervención política: trastocó sus definiciones sobre la guerra, su consideración sobre los aliados y adversarios políticos, su discurso, e incluso en su ubicación en ámbitos particulares como el intelectual y el sindical.

La continuidad de las banderas democráticas y frentepopulistas chocó con el remolino político desatado por la guerra. Y el giro fue brusco. En cuestión de horas y días el PC comenzó a delinear los elementos esenciales de la etapa neutralista: la postura antiguerrera, la impugnación de los distintos bandos imperialistas por igual, la adopción de un antifascismo de caracteristicas diferentes a las del socialismo y otros sectores proaliados, y la exaltación de la consigna de la liberación nacional como el objetivo principal del pueblo argentino ante las diversas formas de opresión imperialista.

Esta brusquedad y este choque con la etapa anterior significó la apertura de un nuevo período de intensa lucha política con todos aquellos sectores que por distintos motivos impugnaron la posición comunista ante la guerra. Donde más se pudo percibir esta ruptura y esta lucha política fue en la relación entre comunistas y socialistas, quienes venian de una estrecha colaboración en el período del Frente Popular, no solo en el plano de la superestructura política, sino también en su intervención en el movimiento obrero, particularmente a través de la CGT.

Sin embargo, no se trató de una ruptura completa. Como hemos señalado, el lenguaje político siguió manteniendo, por preservación (es decir, por la mera necesidad de no perder líneas de diálogo con la base social que lo venía apoyando), o como mecanismo de lucha política (por ejemplo, no dejando en manos de los socialistas la bandera de la "unidad"), elementos que remitian a la etapa del Frente Popular. Más bien 
se produce una hibridez en la política comunista producto del choque entre dos tendencias opuestas: por un lado, el desarrollo local que venía teniendo el PC desde 1935 en adelante que tendia hacia una "unidad democrática" principalmente con el PS y la UCR y, por otro lado, su alineamiento con la IC, que tendía a alejar a los comunistas argentinos de los sectores proaliados.

\section{Bibliografía}

Arévalo, Óscar (1983), El Partido Comunista, Buenos Aires: CEAL.

Barrio de Villanueva, Patricia (2001), El costo de la obediencia. El Partido Comunista Argentino en la encrucijada (1939-1945), Mendoza: Universidad Nacional de Cuyo.

Bisso, Andrés (2005), Acción Argentina. Un antifascismo nacional en tiempos de guerra mundial, Buenos Aires: Prometeo.

Camarero, Hernán (2005), "La izquierda como objeto historiográfico. Un balance de los estudios sobre el socialismo y el comunismo en la Argentina", Nuevo Topo. Revista de historia y pensamiento crítico, I, 1, septiembre-octubre, pp. 77-99.

- (2007), A la conquista de la clase obrera. Los comunistas y el mundo del trabajo en la Argentina, 1920-1935, Buenos Aires: Siglo XXI.

- (2012), "Alcances del sindicalismo único por rama antes del peronismo: la experiencia de la Federación Obrera Nacional de la Construcción (FONC), 1936-1943", Estudios del Trabajo, Buenos Aires.

Camarero, Hernán y Carlos Herrera (2005), "El Partido Socialista en Argentina: nudos históricos y perspectivas historiográficas”, en Hernán Camarero y Carlos Herrera (eds.), El Partido Socialista en Argentina. Sociedad, politica e ideas a través de un siglo, Buenos Aires: Prometeo.

Campione, Daniel (1996), "Los comunistas argentinos. Bases para la reconstrucción de su historia", Periferias. Revista de Ciencias Sociales, I, 1 , segundo semestre, pp. 103-115.

Cane, James (1997), "Unity for the Defense of Culture": the AIAPE and the cultural politics of Argentine antifascism, 1935-1943", The Hispanic American Historical Review, vol. 77, $\mathrm{n}^{\circ}$ 3, Duke University Press, pp. 443-482.

Cattaruzza Alejandro (2005), "Tan lejos y tan cerca. La Guerra de España y la politica argentina", en Diana Wechsler y Marcela Gené, Fuegos cruzados, Córdoba (España): Diputación de Córdoba, pp. 13-26.

Cernadas, Jorge, Roberto Pittaluga y Horacio Tarcus (1998), "Para una historia de la izquierda en la Argentina”, El Rodaballo. Revista de politica y cultura, III, 6/7, otoño-invierno.

Ceruso, Diego Rubén (2010), Comisiones internas de fábrica. Desde la huelga de la construcción de 1935 hasta el golpe de estado de 1943, Buenos Aires: Dialectik. 
- (2015), La izquierda en la fábrica. La militancia obrera industrial en el lugar de trabajo, 1916-1943, Colección Archivos, Buenos Aires: Imago Mundi.

Del Campo, Hugo (1983), Sindicalismo y peronismo. Los comienzos de un vinculo perdurable, Buenos Aires: CLACSO.

Gilbert, Isidoro (2009), La FEDE, alistándose para la revolución, Buenos Aires: Sudamericana.

Godio, Julio (1989), El movimiento obrero argentino (1930-1943). Socialismo, comunismo y nacionalismo obrero, Buenos Aires: Legasa.

Goldar, Ernesto (1986), Los argentinos y la guerra civil española, Buenos Aires: Contrapunto.

Horowitz, Joel (2001), "El movimiento obrero", en A. Cattaruzza, Crisis económica, avance del Estado e incertidumbre politica (1930-1943), t. VII de Nueva Historia Argentina, Buenos Aires: Sudamericana, pp. 239-282.

Lvovich, Daniel y Marcelo Fonticelli (1999), "Clase contra clase. Politica e historia en el Partido Comunista argentino (1928-1935)", Desmemorias. Revista de historia, VI, 23/24, julio-diciembre, pp. 199-221.

Massholder, Alexia (2013), El Partido Comunista argentino y sus intelectuales: originalidad y marginalidad del pensamiento y acción de Héctor P. Agosti, Buenos Aires: Luxemburg.

Matsushita, Hiroschi (1986), Movimiento obrero argentino, 1930-1945. Sus proyecciones en los orígenes del peronismo, Buenos Aires: Hyspamérica.

Montenegro, Silvina (2005), La Guerra Civil española y la politica argentina, tesis de doctorado, Universidad Complutense de Madrid.

Partido Comunista (Comisión del Comité Central) (1947), Esbozo de Historia del Partido Comunista de la Argentina (Origen y desarrollo del Partido Comunista y del movimiento obrero y popular argentino), Buenos Aires: Anteo.

Pasolini, Ricardo (2013), Los marxistas liberales. Antifascismo y cultura comunista en la Argentina del siglo XX, Buenos Aires: Sudamericana.

Petra, Adriana (2018), Intelectuales y cultura comunista. Itinerarios, problemas y debates en la Argentina de posguerra, Buenos Aires: FCE.

Plá, Alberto (1987), "El Partido Comunista de Argentina (1918-1928) y la Internacional Comunista", Anuario Escuela de Historia, Facultad de Humanidades y Artes, UNR, segunda época, 12, Rosario, pp. 339-363.

Prado Acosta, Laura (2015), Los intelectuales del Partido Comunista: Itinerario de Héctor Agosti (1930-1963), Raleigh, NC: A Contracorriente.

Puiggrós, Rodolfo (1973), Las izquierdas y el problema nacional, Buenos Aires: Cepe.

Quijada, Mónica (1991), Aires de República, aires de Cruzada: la guerra civil española en la Argentina, Barcelona: Sendai.

Ramos, Jorge Abelardo (1962), El partido comunista en la politica argentina, Buenos Aires: Coyoacán.

Varone, Domingo (1989), La memoria obrera. Testimonios de un militante, Buenos Aires: Cartago. 